\title{
Using mediated communication to teach vocational concepts to deaf users
}

\author{
Ingrid Teixeira Monteiro, Aline da Silva Alves, Clarisse Sieckenius de Souza \\ Departamento de Informática, PUC-Rio \\ Rua Marquês de São Vicente 225 - 22453-900 Rio de Janeiro, RJ - Brazil \\ \{imonteiro,clarisse\}@inf.puc-rio.br, alinedicict.fiocruz.br
}

\begin{abstract}
This paper presents an in-depth study on how a small group of deaf users reacted while learning abstract vocational concepts in the domain of librarianship, using mediated interaction supported by WNH, a Web Navigation Helper. WNH's purpose is to allow helpers to create mediation dialogs to enable or facilitate helpees' online interaction with Web pages. In our study, deaf employees at a Brazilian library were taught a lesson especially designed for WNH by a deaf librarian who is fluent in Brazilian Sign Language (LIBRAS) and Portuguese. Among the results we were able to see the huge gaps between what a library is for our deaf participants and what it is for non-deaf library professionals and customers. We could also appreciate the role of technologies like WNH in preparing deaf users to interact with Web systems in professional settings.
\end{abstract}

Keywords: Mediated communication, deaf learners, vocational education

\section{$1 \quad$ Introduction}

Sign language is the first (native) language of most deaf people. Brazilian legislation recognizes LIBRAS as the official sign language in this country [1] and says that all deaf citizens must have access to full-length education in LIBRAS. Therefore there is a recommendation that teachers and other education professionals become proficient in LIBRAS [2]. This language, however, does not have a corresponding writing system. As a consequence, deaf Brazilian citizens must use Portuguese when they need to read or write, and Portuguese is a second language [3] for this population.

As is the case with any first language, LIBRAS shapes its speakers' cognition [4]. Thus communication in general and learning in particular are easier when deaf individuals can use sign language. Nevertheless, knowing no other language than LIBRAS can be severely restricting. Work places where deaf individuals must interact with non-deaf, for example, can be extremely difficult if not impossible to access. Vocational training must therefore develop a deaf learner's ability to communicate in a conventional natural language (through lip reading, writing, or other form). Only by being reasonably skilled in communicating with non-deaf customers, for instance, can deaf employees be successful as sales persons, service supervisors or managers. 
This paper presents an in-depth study with a group of deaf participants taking a lesson to learn abstract domain-related concepts as part of a vocational librarianship training activity. The lesson was delivered with the aid of a special technology, namely the Web Navigation Helper (WNH) [5]. WNH is a script-based user agent implemented as an extension of Firefox. With it, Web users who are challenged by interaction patterns used in some application that they need to use can step through rephrased scripted interaction especially designed to remove challenges. This is possible because WNH allows helpers $(i . e$. savvier users with no difficulty to interact with the application at hand) to create mediation dialogs that enable or facilitate online interaction between challenged users (the helpees) and the application. As most content in the Web is delivered in written language, mediation dialogs in WNH tend to follow the pattern and use essentially textual material, too. However, as is also the case in the Web, videos and images can be part of mediation dialogs.

In a previous study [6] with $\mathrm{WNH}$, the author showed that dialogs created by a LIBRAS interpreter could effectively help deaf users overcome certain accessibility barriers and interact with an organizational system designed for non-deaf users. The interpreter used direct instructions in simplified Portuguese and helped deaf users fill out long forms required by an administrative process in their organization. They were able to understand what they had to do with the system and to provide the required information by themselves. Our study makes one step forward and investigates whether WNH can successfully mediate communication about conceptual tasks, rather than operational tasks. To this end, we studied a group of deaf employees at a Brazilian public research institution's library. The goal of the activity proposed to them was to search a library's online catalog. To be successful, they would have to understand and be able to answer questions about basic librarianship concepts required for the task. Participants carried out this learning activity supported by WNH. The mediation dialogs for the study were created by a deaf librarian who was fluent in LIBRAS and Portuguese.

Our study confirmed that LIBRAS is a fundamental requirement in teaching this sort of content to deaf users. The main findings go thus a few steps beyond this. We found clear instances of huge gaps between how deaf participants conceive of library objects and processes compared to the typical conceptualizations made by librarians and library customers. Additionally, we found that WNH is a promising technology for this kind of vocational training. Not only can it be skillfully used to elicit learning requirements for vocational training targeted at this specific population, but it can also be subsequently used to support vocational training practices.

In the next section we present the methodology and procedures of our study. Next, we discuss the main results. In our concluding remarks we point at interesting research topics that can be explored along this path.

\section{Methodology, participants and procedures}

We used qualitative methodology given the exploratory nature of our study. Participants worked at well-known public health research institution with branches in various Brazilian states. It has a permanent social project aiming the inclusion of deaf 
people in the labor market, which is carried out with outsourcing services. At the time of our study, there were 168 deaf workers in their branches.

We followed four major steps of investigation. First, we interviewed the coordinator of the institutional library network to learn about the context and activities carried out by deaf employees. Second, we asked a deaf librarian to elaborate a mini course on library basic concepts needed to use their online catalog. He should use WNH to compose and deliver his mini course. Third we asked three deaf employees to take the lesson using $\mathrm{WNH}$, to do an exercise based on its content and finally to answer a small quiz. Last, we made a semi-structured post-activity interview with participants.

The library network coordinator (henceforth $P-I$, for interviewee), was an experienced librarian, having worked in the institution for many years. She was thoroughly familiar with the challenges faced by deaf employees at the institution's library. The deaf librarian (henceforth $P$ - $C$, for Creator) is deaf since the age of twelve, when he had already learned how to speak, read and write in Portuguese. He can do lip reading and speaks relatively well. P-C learned LIBRAS late, when he joined the institution, because there were many other deaf employees there. P-C holds a degree in librarianship and works in one of the institution's most important libraries.

The remaining participants (henceforth $P-S_{\mathrm{n}}$, for Student ${ }_{\mathrm{n}}$ ) were three deaf employees who volunteered to take P-C's mini course. We recruited volunteers with the following characteristics: 1) profound levels of deafness, from birth or early age; 2) advanced knowledge of LIBRAS and reasonable knowledge of Portuguese; 3) basic computer literacy; 4) working at one of the institution's libraries. These participants' profiles are detailed in Table 1.

Table 1. Deaf participants profile

\begin{tabular}{l|ccccc}
\hline & Gender & Age & Schooling & $\begin{array}{c}\text { Time working } \\
\text { at library }\end{array}$ & $\begin{array}{c}\text { Mastery of } \\
\text { Portuguese }\end{array}$ \\
\hline P-S1 & Male & 40 years old & High-school & 14 years & Low \\
P-S2 & Female & 27 years old & High-school & 6 months & Moderate \\
P-S3 & Male & 40 years old & Incomplete high-school & 6 years & High \\
\hline
\end{tabular}

Mediation dialogs for P-C's mini course were created in two separate 90-minute sessions. Contents and vocational training needs emerged from the interview with P-I. Fig. 1 presents three snippets from the website in reference for the mini course (the library's online catalog). Following conventions in this domain, users type terms search (left side snippet) and results are subsequently shown and browsed at will (center and right snippets). The numbers in Fig. 1 index some of the concepts that were explored in the WNH-supported lesson, indicating the dialog where each was used (see Table 2 for illustrations).

$\mathrm{P}-\mathrm{S}_{1-3}$ took the lesson separately, by running $\mathrm{WNH}$ mediation dialogs previously created by P-C. Each dialog talked about some specific library concept that was used on the corresponding page of the online catalog system. The student should carefully read the dialog and click on "Continuar" (continue) to move on to the next dialog. Fig. 2 shows the dialog that explains the localization code used to identify books on library shelves (see left side bar). Notice that, thanks to scripted navigation, the word "Localização" (localization) is automatically highlighted in the webpage, pointing out 
the exact element that the dialog refers to. In addition to the text used in dialogs, WNH supported additional explanatory and illustrative resources. In Fig. 3 we show an extra dialog accessed through the "Ver exemplo aqui" (See example here) link in the main dialog (Fig. 2). In Fig. 4 we show the screen shown when the "Dúvidas" (doubts) button is pressed. The screen includes short videos with the LIBRAS translation of words appearing in mediation dialogs. P-C conceived of his dialogs in LIBRAS (the first language of his helpees) and then he phrased them in simplified Portuguese. In some cases, P-C found it very challenging to express meanings in Portuguese. He then asked to use images and word translations into LIBRAS ${ }^{1}$.

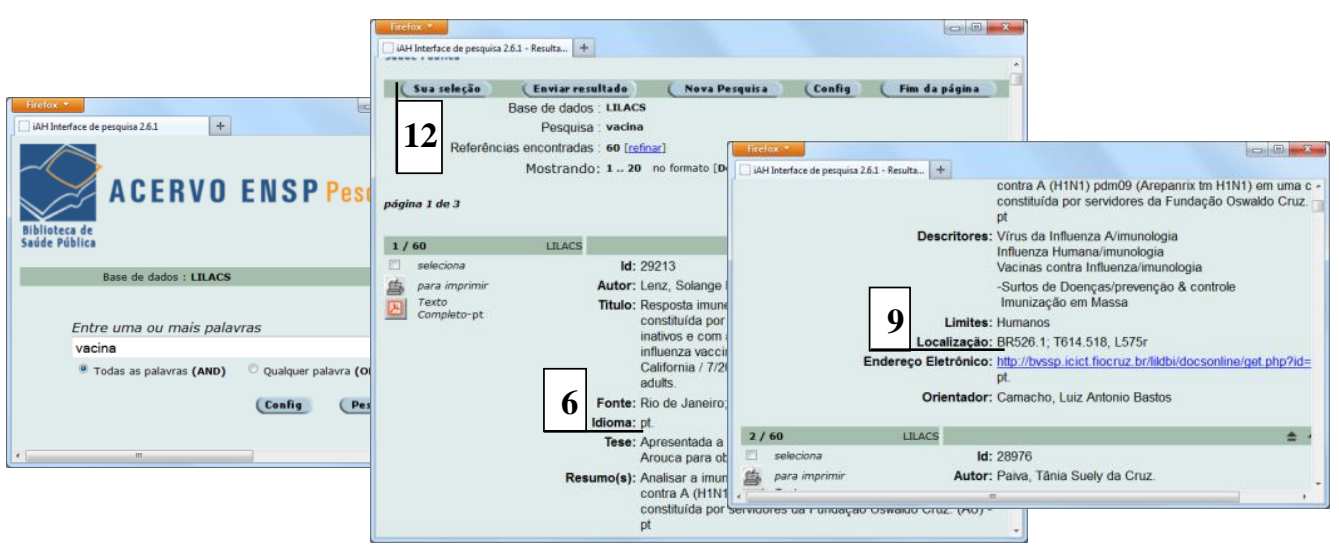

Fig. 1. Search website results page

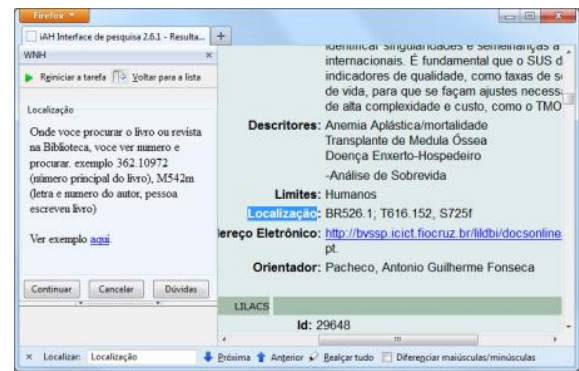

Fig. 2. Localization mediation dialog

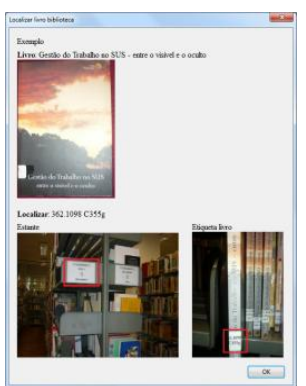

Fig. 3. Extra dialog

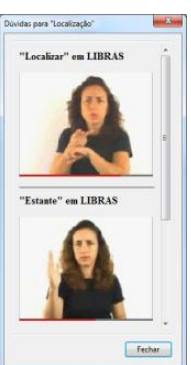

Fig. 4. LIBRAS

The whole lesson was communicated in 13 mediation dialogs. P-C's mini course had two goals: to teach basic library concepts (author, title, abstract, language, descriptors, localization code and link to download); and to teach how to make a basic search in the online catalog system (search terms, search activation, number of returned results and printing of selected results). In Table 2 we see some samples of the final dialogs designed by P-C. They should by no means be taken as the actual corresponding text in English, written by or to deaf individuals. Samples are plainly evocative. We followed certain syntactic patterns of simplification that were verified in

1 All videos in LIBRAS embedded in WNH dialogs were obtained from an online LIBRAS dictionary (http://www.acessobrasil.org.br/libras/) 
Portuguese just to give the reader an idea of the differences in written communication. For information about the English grammar as used by deaf users see [7]. Dialog numbers point to the corresponding element on the system's page (Fig. 1).

Table 2. Samples of content of library lesson dialogs

$$
\text { Dialog } 1 \text { (Welcome dialog) }
$$

We here learn service library, look for books. Start how to look for books, first seek Library staff. Ask how find book. Tell book name or person name who write book. Library staff look for book in computer. Wait he find book. He pick up book. Find not, staff say not have book, Ok! / Look for book in computer, yourself. Ask staff not need. / Open internet page and put [url] / In lesson I explain how to look for book or journal yourself. Ask help library staff not need. / Have doubt and not know meaning word, press doubt button. Words appear in Libras, video explain what word mean. When no doubts button, no word in Libras ok?

\begin{tabular}{|c|}
\hline Dialog 6 (“Idioma"-language) \\
\hline $\begin{array}{l}\text { Language, you speak. Portuguese or English or Spanish. See pt (Portuguese) or en (English) or es (Spanish). } \\
\text { Book or journal write Portuguese, English or Spanish. }\end{array}$ \\
\hline Dialog 9(“Localização”-localization) \\
\hline $\begin{array}{l}\text { Where you search book or journal library. See number and search. Example: } 362.10972 \text { (main book number), } \\
\text { M542m (author letter and number, person write book) / See example here }\end{array}$ \\
\hline Dialog 12 ("Sua seleção"- your selection) \\
\hline $\begin{array}{l}\text { Your selection/ When search book or journal many things appear. Select what good to see after see everything. } \\
\text { Many book or journal appear? You lose important journal or book. When finish select, press selection. What you } \\
\text { select before appear. }\end{array}$ \\
\hline
\end{tabular}

\section{Reception of lesson with conceptual notions in librarianship}

We made close observation of how $\mathrm{P}_{-} \mathrm{S}_{1-3}$ took their lessons individually, interacting with WNH. The duration of the activity was approximately 50 minutes. A LIBRAS interpreter, also a permanent employee at the institution, who knew all participants, helped us to communicate with $\mathrm{P}-\mathrm{S}_{1}$ and $\mathrm{P}-\mathrm{S}_{2}$. $\mathrm{P}-\mathrm{S}_{3}$ could read lips and speak understandably, so we did not need the presence of an interpreter. Also, one of us is a coworker of $\mathrm{P}_{-} \mathrm{S}_{3}$ 's, and thus we could communicate satisfactorily with this participant.

The dynamics of the activity was as follows. Before starting the lesson, the interpreter explained the activity to the participant. Then the participant interacted with WNH. At the end of the lesson, the participant was asked to take a quick test, where we could see how much was learned. The test included a few questions and a short task that participants should perform. The interpreter orally translated the content of test questions into LIBRAS.

An observation of how participants read the WNH-supported lesson in simplified Portuguese gave us valuable insights. P-S1 was the fastest reader (approx. 8 minutes to cover the whole material). He moved quickly from one dialog to the next. Only when he was reading the dialog explaining the "electronic address" field (with a link to download journal article), he seemed to closely follow guidelines presented in the dialog (like "you press blue color computer"). He clicked on the link, downloaded the file, opened it and browsed its pages. Our own reading of P-C's intent in such cases was that he just intended to tell the student about what he might do when he saw the link (not that he actually did it). Accessing the link was not a point in lesson. This observation, should be further investigated in view of the use of verbal modality in the simplified Portuguese displayed in P-C's dialogs (for example, we should investigate the differences in communication of what you must do and what you might do). 
$\mathrm{P}-\mathrm{S}_{2}$ took about 15 minutes to complete the entire lesson. Various aspects of her interaction with WNH caught our attention. To begin with, she gesticulated spontaneously as she read the lesson. In the interpreter's word: "She translated what she was reading into LIBRAS." This is powerful evidence of the cognitive burdens of having to handle communication in a second language (compared to her more native LIBRAS). On some occasions, $\mathrm{P}-\mathrm{S}_{2}$ had doubts about the text produced by $\mathrm{P}-\mathrm{C}$. For example, at some point she asked the interpreter if she was supposed to click on a link (which we could take again as a question related to the use of modal verbs in P-C's simplified Portuguese).

In the document language dialog (6 in Table 2), she confirmed the meaning of the words "English" and "Portuguese" with the interpreter. She intriguingly interpreted the word "Spanish" as meaning "United States". The interpreter corrected the misunderstanding by translating "Spanish" into LIBRAS. Possibly the confusion sprang from both words starting with the same letters in Portuguese ("ESpanhol" and "EStados Unidos"). To us, this is a pointer to an interesting research question, related to the iconic reading of written words, so to speak. Similarity of form (starting with the same letters) might prevail over semantic relatedness (being a spoken language).

$\mathrm{P}-\mathrm{S}_{2}$ struggled to understand the dialogs explaining how to print selected books (12 in Table 2 is part of those). She apparently missed a script step in between subsequent dialogs, which caused the web page to change content. She did not realize that the page content had changed from one step to the other. This is an important finding to fine-tuning $\mathrm{WNH}$ for this context of use.

$\mathrm{P}-\mathrm{S}_{3}$ needed 11 minutes to finish the lesson. In the dialog about searching, he typed the word "disease" directly on the system's page textbox. This was literally the instruction written in the dialog ("You put name search want. Example: you write disease and press search button"), but the WNH script would have done it automatically for him. $\mathrm{P}-\mathrm{S}_{3}$ moved quickly through the remaining dialogs, apparently not reading the content in them. This comfortable situation changed when he reached the dialog about selecting of books. Even if he clearly noticed referred elements being automatically highlighted in the web page, he read and reread the text, very carefully. He also accessed the doubts area. At the end of the second dialog about this topic (12 in Table 2 ), he explicitly said that he did not understand what was being said. The interpreter gave him additional explanation and $\mathrm{P}-\mathrm{S}_{3}$ seemed to understand. In the last dialog of the lesson, $\mathrm{P}-\mathrm{S}_{3}$ did the same as $\mathrm{P}-\mathrm{S}_{2}$, he read the text and instantly translated it into LIBRAS.

Once the lesson was finished we proposed an exercise to participants. They should search for the word "vaccine", analyze results and then answer 6 questions (Table 3).

Table 3. Questions about activity

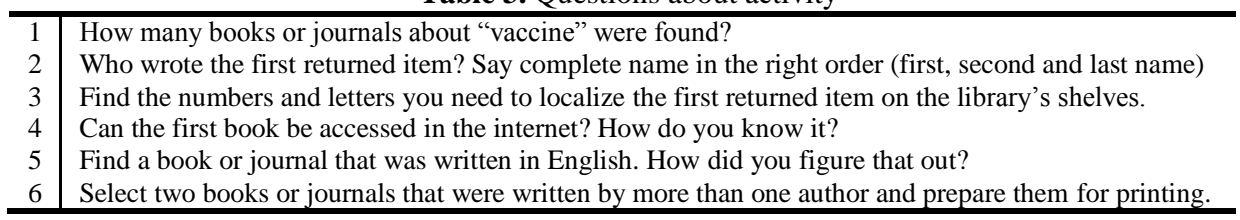

The general performance of participants is summarized in Table 4. Column 1 indicates the result of the first attempt of answer (Success/Failure). Column 2 corresponds 
to the result after the interpreter rephrased the question or the participant reread the corresponding dialog. In order to have a coherent interpretation about this table, it is useful to know what concepts the participants already knew before they took the lesson. They are summarized in Table 5.

Table 4. Participants performance in activity

\begin{tabular}{|c|c|c|c|c|c|c|c|}
\hline & & \multicolumn{2}{|c|}{ P-S1 } & \multicolumn{2}{|c|}{$P-S 2$} & \multicolumn{2}{|c|}{$P-S 3$} \\
\hline \multicolumn{2}{|r|}{ Questions } & 1 & 2 & 1 & 2 & 1 & 2 \\
\hline 1 & Find References & $\mathrm{F}$ & $\mathrm{F}$ & S & & $\mathrm{S} / \mathrm{F}$ & $\mathrm{S}$ \\
\hline 2 & Author (find name) & $\mathrm{F}$ & S & S & & $\mathrm{S}$ & \\
\hline 2 & Author (order name) & $\mathrm{F}$ & $\mathrm{F}$ & $\mathrm{F}$ & $\mathrm{F}$ & S & \\
\hline 3 & Localization & $\mathrm{F}$ & $\mathrm{F}$ & $\mathrm{F}$ & $S$ & S & \\
\hline 4 & Electronic address & $\mathrm{S}$ & & S & & $\mathrm{S}$ & \\
\hline 5 & Language & $\mathrm{F}$ & $\mathrm{F}$ & $\mathrm{F}$ & S & S & \\
\hline 6 & Selection (find authors) & $\mathrm{F}$ & $\mathrm{F}$ & $\mathrm{F}$ & $\mathrm{F}$ & $\mathrm{S}$ & \\
\hline 6 & Selection (prepare print) & $\mathrm{F}$ & $\mathrm{F}$ & $\mathrm{F}$ & $\mathrm{F}$ & $\mathrm{S} / \mathrm{F}$ & $\mathrm{S}$ \\
\hline
\end{tabular}

Table 5. Previous known words

\begin{tabular}{c|l|ccc}
\hline \multicolumn{2}{l|}{} & $\boldsymbol{P}$-S1 & $\boldsymbol{P S}$-2 & $\boldsymbol{P S}$-3 \\
\hline $\mathbf{1}$ & Reference & Yes & No & Yes \\
$\mathbf{2}$ & Author & Yes & No & Yes \\
$\mathbf{3}$ & Localization & Yes & No & Yes \\
$\mathbf{4}$ & Electronic & No & No & Yes \\
& address & & & \\
$\mathbf{5}$ & Language & Yes & No & Yes \\
$\mathbf{6}$ & Title & No & Yes & Yes \\
$\mathbf{7}$ & Abstract & No & No & Yes \\
$\mathbf{8}$ & Descriptors & No & No & No \\
\hline
\end{tabular}

Table 4 shows that participants' performance differed significantly, which is good for an exploratory study designed to probe the depth of an unknown situation. Although $\mathrm{P}_{-} \mathrm{S}_{1}$ read the lesson more quickly than others, the only question that he could answer correctly in his first attempt was about "electronic address". Suggestively, this concept was explored in the dialog where he spent most time exploring links, etc. As shown in Table 5, $\mathrm{P}-\mathrm{S}_{1}$ did not know what "electronic address" was before he took the lesson, from which we conclude that he learned this during the activity. However, even after rereading the corresponding dialogs, he failed answer most of the other questions correctly. At a second attempt, he managed to tell the name of the author of the first returned item (Table 4). $\mathrm{P}-\mathrm{S}_{2}$ gave three correct answers at her first attempt (Table 4), all of them involved unknown concepts (Table 5). With further help, she could correctly answer two more questions. Not surprisingly, $\mathrm{P}-\mathrm{S}_{3}$ did very well. "S/F" in Table 4 indicates that $\mathrm{P}-\mathrm{S}_{3}$ answered the question correctly but did not strictly follow what was taught in lesson. As a courtesy, in cases of repeated failure, the interpreter explained the answer in LIBRAS to the participant.

It took all participants some time to give a correct answer. They either looked for a clue in the webpage or engaged in "trial and error" mode. For example, to answer the

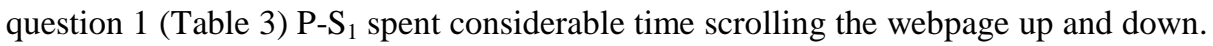
Eventually, the interpreter offered some help, saying that the dialog explained how he could find the number of items returned by the search. We asked P-S $\mathrm{S}_{1}$ if the text was difficult and he said that it was complicated. In the dialog explaining localization on shelves, the interpreter told us, on the side: "This should be easy for him. It's his job: to look for books on the library's shelves". Nevertheless, $\mathrm{P}-\mathrm{S}_{1}$ failed. After a number of unsuccessful turns, the interpreter directly asked: "What do you need to know in order to find a book on the shelf?" She then translated his answer to us: "He said he needs the title, the page number... He did not understand [the concept]." When the interpreter eventually explained the right answer to him, $\mathrm{P}-\mathrm{S}_{1}$ said the numbers and letters were very small, hard to see, and he was used to doing something different.

In the dialog about the document's language, after the first failure, the interpreter asked if one of the books was written in Portuguese or in English. P-S $\mathrm{S}_{1}$ correctly said 
that it was Portuguese. When asked how he knew it, he pointed to the English version of the book's title and said: "Only this in English". As most information in the item's entry was written in Portuguese, he concluded that the item's language must be Portuguese. At one point, he said another document was written in Spanish because he saw to the word "México" in one of the entry's fields. This kind of metonymic reasoning, taking the country of publication or the language of information in entry fields for the language of the document is an interesting cognitive strategy to be further explored in research. Its significance for vocational training is clear. Along these lines, $\mathrm{P}-\mathrm{S}_{1}$ 's reasoning to answer question 6 (Table 3) was also revealing. At first, he looked through the webpage, searching for some clue to find an item with more than one author. His first attempt was to point at the content of the "Descriptors" field. The second was to point at content of the "Author's keywords" field. The latter was probably due to the presence of the word "author" in that field. But the former was only elucidated during the interview. When we asked if he knew the word "descriptors" before he took the lesson, he answered: "person wrote book". It then became clear that he was confused with the similarity between two words in Portuguese: "descritor" (descriptor) and "escritor" (writer). The cognitive gaps in this case were considerable, since the content of the "Descriptors" field were apparently taken as valid author names.

$\mathrm{P}-\mathrm{S}_{2}$ also gave us evidence of interpretive issues. In the dialog about localization, $\mathrm{P}-\mathrm{S}_{2}$ focused in fields whose content had sequences of numbers and letters. She used the sign "tag" to ask the interpreter if she was supposed to search for the localization code shown on books tags, but even then she failed to find the answer. After rereading the dialog, she finally understood that she should be looking for the "Localization" field and gave the right answer. The dialog on language $(6$, in Table 2$)$ was again a source of insights. $\mathrm{P}-\mathrm{S}_{2}$ tried to guess the language by looking at words in field contents, but not reading what the "Language" field said. After a while the interpreter pointed to "pt" and asked her what it meant. She answered she did not know this word (she missed or forgot the content of the lesson). In the question about coauthored items, she tried to answer by counting the words in a single author's name, instead of counting how many authors were listed in the field.

$\mathrm{P}-\mathrm{S}_{3}$ gave us unexpected but correct answers for two questions. In question 1 , he told the correct number of results, but he inferred this from the repetition of the number " 60 " in each of the listed items: " $1 / 60 "$, " $2 / 60 "$, " $3 / 60$ ", etc. He did not look for the value of "Referências encontradas" (found references) field, which was what the lesson said should be done in this case. Likewise, he selected books and journals as a side effect of clicking on individual print buttons, rather than selecting them in the way the lesson indicated.

The post-test interviews finally gave us important evidence of challenges faced by participants. For example, although $\mathrm{P}_{-} \mathrm{S}_{1}$ started saying that the lesson was easy and that he had no problems, when asked about the content of textual explanations he said that he understood "more or less, a little bit". He also told us that he could learn the words "language" and "localization", which he did not know before.

$\mathrm{P}-\mathrm{S}_{2}$ confirmed during her interview one of the points raised by the library's coordinator $(\mathrm{P}-\mathrm{I})$, that alphabetical and numerical ordering is a recurring problem faced by 
deaf workers in the institution libraries. In the interview, $\mathrm{P}-\mathrm{S}_{2}$ said that the single activity she considered difficult in her job was dealing with localization codes. She said: “A, B, C, D, sometimes I read wrong and there are the numbers..." Her opinion about the textual material in the lesson, in general, was quite positive. She considered the text easy and understandable. The Portuguese was simple and she appreciated the correspondence between the dialog content and what happened on the system's webpage.

$\mathrm{P}_{-} \mathrm{S}_{3}$ 's opinions were expressed even before the interview started. While he was still running the lesson he said that after careful reading he could finally understand but that the activity was difficult at first time one use it, it is difficulty. He thought some practice was needed to really be able to learn. When asked if he thought other deaf students would understand explanations presented in the lesson, he said that if there was someone to show how it worked, it would be easier, because, in general, deaf people have problems to read and understand sentences. However, he said that he liked the text and the explanations that he learned some words (like "select" and "descriptors"). He also learned how to print more than one book. The problem with the lesson's format, in his opinion, was that: "one reads the first time, one learns content, but after some time, one forgets". This is a clear recommendation for lessons with more fixation tasks.

\section{Concluding Remarks}

Hearing impairment can be more critical than others mainly because it affects one of our most important abilities - communication. According to the world report on disability [8] "individuals with communication difficulties, such as hearing impairment or speech impairment, are at a significant social disadvantage, in both developing and developed countries." (p.172)

Our study confirmed what we already know, that is, that sign language is the main form of communication for deaf users, and that it must be used in vocational training. However, our perspective on vocational training was to investigate the potential of $\mathrm{WNH}$ as a means to leverage the linguistic skills of deaf individuals whose job requires that they interact with hearing people who do not know LIBRAS. Moreover, professional progress in their case requires that they learn to use computer technology (online catalogs, for example) that is designed to attend the needs of the majority of the library's customers. Even if there were optimal accessibility tools in place to allow deaf employees to understand and use this technology effectively, part of their job would be to help non-deaf customers use the system and/or to communicate with the through the system. In short, if vocational training must enable professional growth and progress in the context of our study, then it should prepare deaf learners to communicate more effectively with non-deaf co-workers and customers.

Our reported findings show the magnitude of cognitive gaps persisting over considerable periods of time (see "Time working at library" in Table 1) in our participants' conceptualization of the work place around them. It also shows the amount of effort that deaf individuals may be willing to make when trying to learn something. It is noteworthy that none of our participants said they simply did not know the answer 
to a question and gave up looking for an answer. Quite contrarily, they tried again and again until they succeed by themselves or we explained to them how to find the correct answer. Our in-depth observation shows that the teaching and learning of abstract concepts with the aid of computer technology was much harder than teaching and learning operational procedures, which has been done in a previous study [6].

Nevertheless, WNH proved to be a very promising tool for vocational teachers engaged with deaf learners. At first it can be used to probe the needs of learners in terms of communicative skills, domain content and learning strategies. Afterwards, it can be used to support and effect the teaching-learning process with considerable advantages. For instance, as a Web-based tool, WNH can easily integrate multiple modalities of communication like text, images and video. It can also let the learners pace their learning as it best fits them, on an individual basis. Finally, the Web infrastructure can be used to introduce deaf learners smoothly into the communicative realm of non-deaf Web users. In the context of our study, for example, advanced vocational training might teach deaf library workers how to carry out simple asynchronous computermediated communication protocols with library clients. The social benefits of a successful initiative along these lines would be invaluable.

Acknowledgement. Authors thank FAPERJ, CNPq and IBM Research for supporting this research.

\section{$5 \quad$ References}

1. Brasil. Lei n. 10.436, de 24 de abr. de 2002. Dispõe sobre a Língua Brasileira de Sinais Libras e dá outras providências. (2002)

2. Brasil. Decreto $N^{\circ} 5.626$ de 22 de Dezembro de 2005. Regulamenta a Lei no 10.436, de 24 de abril de 2002. (2005)

3. Kozlowski, L. O modelo educacional Bilíngue no INES; Anais do VI Seminário Nacional do INES - Surdez e diversidade social: 2001; VI Seminário Nacional do INES. Rio de Janeiro. (2001)

4. Silva, V. Educação profissional para surdos: uma vivência político-pedagógica no Centro Federal de Educação Tecnológica de Santa Catarina. Ponto de vista: Revista de Educação e Processos Inclusivos, 5, 151-178. (2003).

5. Monteiro, I.T. Acessibilidade por diálogos de mediação: Desenvolvimento e avaliação de um assistente de navegação para a Web. Rio de Janeiro: Pontifícia Universidade Católica do Rio de Janeiro. 198 p. MSc Dissertation (2011)

6. Alves, A. S. Estudo do uso de diálogos de mediação para melhorar a interação de surdos bilíngues na Web. Rio de Janeiro: Universidade Federal do Estado do Rio de Janeiro. 156 p. MSc Dissertation (2012).

7. Berent, G. P. The acquisition of English syntax by deaf learners. Handbook of second language acquisition, 469-506. (1996)

8. World Health Organization (WHO). The world report on disability. World Health Organization. Retrieved from http://www.ncbi.nlm.nih.gov/pubmed/22726850 (2011) 